\title{
Contêineres Metálicos para Instalações Provisórias em Canteiros de Obras no Brasil
}

\author{
Débora Cristina Rosa Faria da Costa \\ Racine Tadeu Araújo Prado
}

\section{Introdução}

Os contêineres metálicos utilizados como instalações provisórias de canteiros de obra diferem dos contêineres marítimos quanto ao material de composição e à espessura das paredes. Enquanto os contêineres marítimos são confeccionados em aço corten, com espessura em torno de $1,3 \mathrm{~mm}$, os contêineres para canteiros de obras são compostos predominantemente de aço galvanizado, com espessura em torno de 0,65 mm, diferença de configuração que atribui aos contêineres marítimos peso duas vezes maior.

No setor da construção civil, existe um padrão construtivo para os contêineres, relacionado principalmente às dimensões adequadas para o transporte sobre caminhão, embora haja variações de composição de materiais e dimensões, dentro da gama de produtos disponíveis no mercado brasileiro. O padrão mais utilizado apresenta altura útil de 2,5 m, largura de 2,4 m e comprimento variável, frequentemente baseado na modulação de $3 \mathrm{~m}$, ou seja, há produtos com 3, 6 e $9 \mathrm{~m}$ de comprimento. São comercializados, em grande parte dos casos, sem qualquer tratamento térmico nas superfícies verticais. Muitos dos produtos disponíveis no mercado possuem um forro de $2 \mathrm{~cm}$ de poliestireno expandido (EPS) junto à superfície interna da cobertura, cuja função é o isolamento térmico, acrescido de uma chapa dura de material derivado de madeira, com espessura de $2,5 \mathrm{~mm}$, para melhoria da qualidade do acabamento. 
O setor da construção civil brasileiro adota diferentes tipologias de sistemas construtivos para as instalações provisórias de canteiros de obras, dentre as quais encontram-se os contêineres metálicos. A utilização de contêineres metálicos como instalações provisórias em canteiros de obras tem crescido, visto ser uma tipologia que apresenta vantagens sobre as demais, normalmente empregadas no mercado brasileiro. Características como rapidez e praticidade na montagem, facilidade de transporte e reutilização, assim como o baixíssimo potencial de geração de resíduos, são particularmente atraentes no momento da especificação das instalações para canteiros de obras. A Tabela 1 apresenta as principais características dos sistemas mais utilizados.

Tabela 1 - Comparação entre diferentes sistemas de instalações provisórias para canteiros de obras utilizados atualmente no Brasil.

\begin{tabular}{|c|c|c|c|c|c|}
\hline Item & $\begin{array}{l}\text { sistema } \\
\text { tradicional } \\
\text { de chapas } \\
\text { de madeira } \\
\text { compensada }\end{array}$ & $\begin{array}{l}\text { pré-moldado } \\
\text { de madeira }\end{array}$ & $\begin{array}{l}\text { contêineres } \\
\text { metálicos }\end{array}$ & $\begin{array}{l}\text { construções } \\
\text { metálicas } \\
\text { desmontáveis }\end{array}$ & $\begin{array}{l}\text { fibra } \\
\text { plástica }\end{array}$ \\
\hline $\begin{array}{l}\text { uso de mão de obra } \\
\text { para montagem }\end{array}$ & alta & média & baixa & média & baixa \\
\hline $\begin{array}{l}\text { tempo de montagem/ } \\
\text { desmontagem }\end{array}$ & alto & médio & baixo & baixo & baixo \\
\hline grau de industrialização & baixo & médio & alto & alto & alto \\
\hline $\begin{array}{l}\text { potencial de } \\
\text { reutilização }\end{array}$ & $\begin{array}{l}\text { baixo/ } \\
\text { nenhum }\end{array}$ & alto & alto & alto & alto \\
\hline versatilidade & alta & alta & alta & alta & baixa \\
\hline $\begin{array}{l}\text { grau de complexidade } \\
\text { da montagem }\end{array}$ & baixo & médio & baixo & baixo & baixa \\
\hline custo aluguel & baixo & - & alto & - & alto \\
\hline custo compra & baixo & baixo & alto & alto & alto \\
\hline $\begin{array}{l}\text { necessidade de } \\
\text { execução de fundação }\end{array}$ & alta & média & baixa & baixa & baixa \\
\hline $\begin{array}{l}\text { complexidade de } \\
\text { transporte }\end{array}$ & baixa & baixa & baixa & baixa & baixa \\
\hline $\begin{array}{l}\text { condição de conforto } \\
\text { térmico }\end{array}$ & média & média & baixa & baixa & - \\
\hline $\begin{array}{l}\text { potencial de geração de } \\
\text { resíduos }\end{array}$ & alto & alto & baixo & baixo & alta \\
\hline vida útil em anos & 3 & 3 & 12 a 18 & 12 a 18 & - \\
\hline
\end{tabular}

Elaborada a partir de Saurin e Formoso, 2006 e Oliveira e Leão, 1997. 
A Tabela 1 organiza-se de modo a qualificar como positiva, mediana ou negativa cada uma das características apresentadas pelas principais tipologias utilizadas como instalações provisórias nos canteiros de obra. As células em vermelho apontam características negativas; as células amarelas, as características neutras; e as células verdes, as características positivas para cada quesito analisado.

Pode-se constatar, com base nas características avaliadas, que o sistema tradicional de chapas de madeira compensada é o que apresenta maior quantidade de pontos negativos, enquanto o sistema de contêineres metálicos apresenta a maior quantidade de itens positivos, evidenciando deficiências no que se refere aos custos iniciais de aquisição e aos níveis de conforto ambiental apresentados.

Saurin e Formoso (2006) realizaram estudo comparativo que permitiu a avaliação dos custos ao longo do tempo para três tipologias de instalações provisórias, conforme Figura 1: os contêineres metálicos, os compensados de madeira e um sistema mesclado entre contêineres utilizados no início e fim da obra, intercalados com o uso das instalações do próprio edifício em construção.

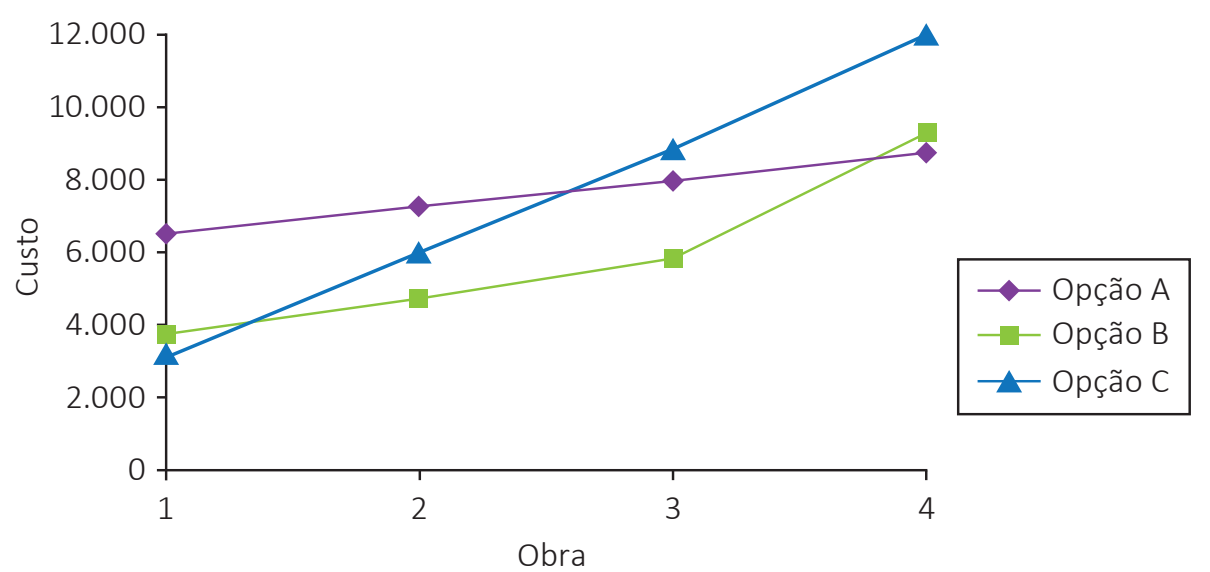

Figura 1-Comparação de custos entre as diferentes modalidades de instalações provisórias ao longo de sua utilização em sucessivas obras, segundo Saurin e Formoso, 2006.

Onde:

- Opção A: contêineres metálicos adquiridos definitivamente;

- Opção B: sistema racionalizado em chapas de compensado de madeira;

- Opção C: contêineres alugados durante três meses e utilização das instalações do edifício em construção nos demais períodos.

Como podem ser observados no gráfico da Figura 1, os custos iniciais são maiores para a utilização de contêineres metálicos, devido ao investimento feito para 
a aquisição, mas com o passar do tempo e a possibilidade de reutilização maior do que o sistema de compensados de madeira, os custos tendem a apresentar menor crescimento se comparados aos demais sistemas.

Segundo pesquisa de preços de contêineres realizada com fornecedores do mercado brasileiro no mês de junho de 2012, o valor da aquisição dos contêineres metálicos para instalação provisória em canteiros de obras equivaleria em média a 24 vezes seu custo mensal com aluguel. Os custos de manutenção, segundo um dos fabricantes consultados, aproximam-se 30\% do valor de aquisição, mas serão empregados somente após 10 anos de utilização do contêiner. Contudo, é possível amenizar os custos do investimento inicial de aquisição de contêineres optando pela locação dos sistemas modulares, modalidade disponível em muitas das empresas fornecedoras.

Como ressaltam Saurin e Formoso (2006):

Seja qual for o sistema utilizado, devem ser considerados os seguintes critérios: custos de aquisição, custos de implantação, custos de manutenção, reaproveitamento, durabilidade, facilidade de montagem e desmontagem, isolamento térmico e impacto visual. A importância de cada critério é variável conforme as necessidades da obra.

A durabilidade dos contêineres, segundo alguns fabricantes, é estimada em dez anos, sem significativa manutenção, sob as condições agressivas habitualmente existentes em canteiros de obras, sendo consideravelmente ampliada se reformados após esse período. Desse modo, das características negativas dos contêineres apresentadas na Tabela 1, as questões referentes aos custos de aquisição ou locação passam a ficar minimizadas quando se considera sua durabilidade e a possibilidade de reutilização.

O objetivo do presente trabalho é propor adequações às instalações provisórias em contêineres metálicos para canteiros de obras, a fim de que se possam atingir melhores condições de conforto térmico em sua utilização, bem como a redução da demanda energética quando do uso sob condicionamento artificial.

\section{Contêineres para Canteiros de Obras no Mercado Brasileiro}

O setor da construção civil adota um padrão construtivo para os contêineres metálicos, embora haja variações de composição de materiais e dimensões, dentro da gama de produtos disponíveis no mercado brasileiro. O padrão mais utilizado apresenta altura útil de 2,5 m, largura de 2,4 m e comprimento variável, frequentemente baseado na modulação de $3 \mathrm{~m}$. As paredes em aço possuem espessura frequentemente inferior a $1,0 \mathrm{~mm}$. 
Nos canteiros de obras, são majoritariamente utilizados nas funções de apoio administrativo das obras, como nos escritórios, refeitórios, sanitários e depósitos, ou então como alojamentos para os trabalhadores. Tais características de uso são determinantes para a compreensão de que - no caso dos contêineres - a abordagem quanto aos requisitos de conforto térmico e índices de temperatura adequados para o trabalho ou o descanso faz-se necessariamente diferente, conforme o uso a que se destinam, ainda que o projeto básico do contêiner seja o mesmo para os diferentes usos.

Embora os contêineres sejam ambientalmente adequados em muitos aspectos, suas características térmicas são extremamente insatisfatórias, o que acarreta a utilização praticamente constante de climatizadores de ar, a fim de viabilizar a ocupação humana. Esse fato contribui para o aumento do consumo de energia comparativamente a outros sistemas construtivos utilizados como instalações provisórias em canteiros de obras. Segundo Santamouris e Kolokotsa (2013), o volume de energia demandada pelo setor da construção civil varia conforme o país, permanecendo entre 35 a 40\% da demanda mundial por energia, se consideradas as etapas de construção e o pósocupação. Os mesmos autores ainda afirmam que a demanda por condicionamento de ar corresponde a 15\% do consumo mundial de energia.

Durante a realização da pesquisa experimental de mestrado que embasou este capítulo (COSTA, 2015), foram realizadas visitas a inúmeros canteiros de obras cujas instalações provisórias foram montadas em contêineres metálicos no município de São Paulo. A queixa mais frequente por parte dos trabalhadores foi quanto ao calor excessivo dentro das instalações, o que praticamente inviabilizaria a permanência humana sem condicionamento artificial. Contudo, durante uma das visitas ao canteiro, ocorrida em um dia extremamente frio de inverno, presenciou-se que, sob aquelas condições, o conforto térmico também estaria comprometido.

Dentre a imensa variedade de dimensões dos contêineres produzidos no mercado brasileiro destinados às instalações para canteiros de obras, há diferença entre os tipos de superfícies de acabamento e o tipo de tratamento térmico, de acordo com a finalidade a que se destinam. Para a presente pesquisa, interessam particularmente os contêineres destinados ao trabalho em escritório - haja vista que é o local onde ocorre maior tempo de permanência de trabalhadores - e os contêineres destinados aos alojamentos, nos quais os trabalhadores passam o tempo de repouso. As tipologias mais representativas da variedade de acabamentos e tratamentos térmicos serão apresentadas a seguir, tomando o módulo básico de 6,0 m de comprimento como referência, já que é um produto fornecido por grande parte das empresas do setor.

\subsection{Contêineres em Aço sem Tratamento Térmico}

Os contêineres em aço sem tratamento térmico têm sido utilizados nos canteiros de obras brasileiros tanto nos escritórios quanto nos alojamentos, como consta da 
Figura 2. A fim de contornar o desconforto térmico advindo do uso dessas instalações, adota-se a climatização artificial, que, consequentemente, incrementa os custos de obra, demandando grande quantidade de energia.
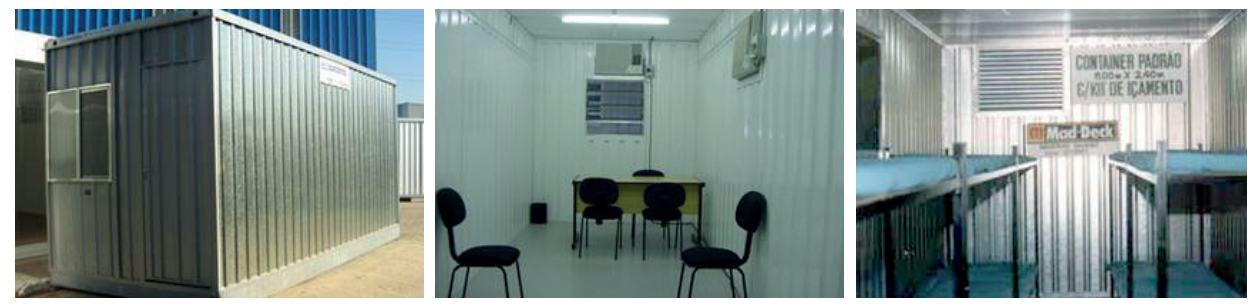

Figura 2 - Contêineres Metálicos sem tratamento térmico. Fontes: http://www.eurobras. com.br/view?id=eb13-0\&cat=tradicional e http://soldatopo.com.br/site/?produtos=belichesmetalicos-soldatopo.

\subsection{Contêineres Metálicos com Tratamento Térmico}

O mercado brasileiro oferece módulos tratados termicamente. Dentre as composições mais frequentemente desenvolvidas, é comum a utilização do isopor entre a chapa de aço externa e o forro interno, feito de material plástico ou de aglomerado de madeira. Tal tipologia de tratamento térmico aparece, em alguns casos, somente nas coberturas, ou ainda em coberturas e paredes. Adotam-se também, para cobertura e paredes, os painéis sanduíche, compostos por duas chapas de aço, normalmente pintadas de branco - dispostas como revestimento interno e externo - com a camada intermediária em poliuretano e espessura de $50 \mathrm{~mm}$, como apresentado na Figura 3.
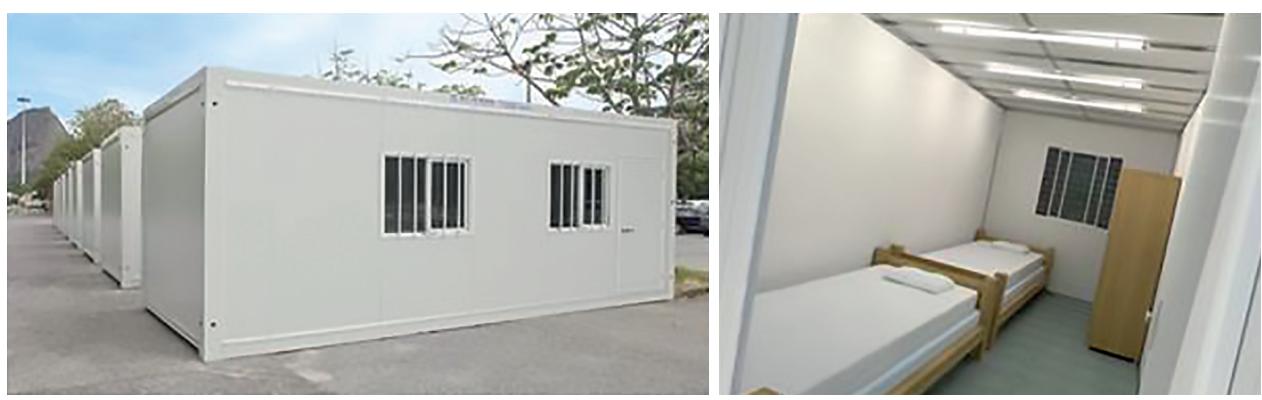

Figura 3 - Contêineres metálicos com tratamento térmico. Fonte: http://www.nhjdobrasil. com.br/pt-br/produtos/modulo-habitavel/ e http://www.eurobras.com.br/view?id=ebta10-0\&cat=origin 


\section{Método de Pesquisa}

A presente pesquisa foi executada por método experimental, com medições térmicas realizadas initerruptamente durante um ano. $O$ experimento localizou-se no município de Mairinque-SP, pertencente à Zona Bioclimática n 3 (ABNT, 2005). Foram utilizados três modelos experimentais em escala natural, conforme especificações a seguir:

Contêiner 1: em aço galvanizado, com 3 m de comprimento, 2,4 m de largura e 2,5 $\mathrm{m}$ de altura, piso em compensado de madeira de $2 \mathrm{~cm}$ de espessura, com revestimento plástico imitando madeira, disposto a $28 \mathrm{~cm}$ de altura do solo, contendo uma janela nas dimensões 0,99 $\mathrm{m} \times 0,92 \mathrm{~m}$ e porta de $0,77 \mathrm{~m} \times 2,11 \mathrm{~m}$, ambas do mesmo material da composição, mantidas fechadas durante o período de medições. Possui insterstícios que permitem a passagem do ar nas junções entre a cobertura e as paredes verticais.

Contêiner 2: composição idêntica à do Contêiner 1. A cobertura, no entanto, é acrescida de uma camada interna de poliestireno expandido (isopor) de $2 \mathrm{~cm}$ de espessura e de uma chapa dura de material derivado de madeira revestido internamente com fórmica bege fosca (Eucaplac). As junções do forro não permitem infiltração de ar como ocorre no Contêiner 1. As vedações verticais contém poliestireno de $2 \mathrm{~cm}$ de espessura nos interstícios existentes devido ao perfil do aço corrugado utilizado entre a chapa de aço e a chapa de madeira. O piso é confeccionado em compensado de madeira 2 $\mathrm{cm}$ de espessura, acrescido de revestimento plástico imitando madeira ${ }^{1}$.

Contêiner 3: composição idêntica à do Contêiner 1. Nesse Contêiner, no entanto, aplicou-se uma camada de $0,25 \mu \mathrm{m}$ de revestimento branco refletivo externamente, de forma homogênea, nas quatro superfícies verticais incluindo porta e janela - e na cobertura.

As medições foram executadas em todas as superfícies internas e externas da envoltória, com exceção da parte externa do piso, a partir da instalação de sensores térmicos, conectados a um datalogger.

1 A escolha de tipologia do Contêiner 2 deveu-se ao fato de este ser um dos produtos disponibilizados pelo fabricante ao mercado, na ocasião do experimento, conforme solicitado pelos pesquisadores. 


\section{Resultados}

\subsection{Avaliação do Comportamento Térmofísico de um Contêiner Metálico para Canteiro de Obras sem Tratamento Térmico na Envoltória}

Como apresentado na análise qualitativa das tipologias mais utilizadas como instalações para canteiros de obras brasileiros, observa-se que os contêineres metálicos possuem características que os tornam instalações ambientalmente amigáveis, considerando sua flexibilidade de usos, rapidez na montagem e desmontagem, grande possibilidade de reutilização, longa vida útil e baixa geração de resíduo. Seu aspecto térmico, no entanto, é insuficiente, o que frequentemente leva à necessidade de condicionamento artificial, acarretando alto consumo energético ou situações de desconforto quando empregado sob ventilação natural.

O aspecto térmico dos contêineres metálicos foi objeto de pesquisa experimental (COSTA, 2015), na qual foram realizadas medições em contêineres reais durante um ano, para que se pudesse caracterizar o comportamento termofísico dessa instalação, a fim de desenvolver estratégias de tratamentos térmicos da envoltória, no sentido de minimizar a necessidade de utilização de condicionamento artificial para a obtenção de níveis de conforto mais adequados em seu interior.

As análises experimentais foram realizadas no município de Mairinque - SP, situado na Zona Bioclimática Brasileira $n^{\circ} 3$ (ABNT, 2005), cujo clima pode ser descrito como tropical de altitude, com temperaturas amenas e predominância de chuvas no verão e noites frias no inverno. A caracterização termofísica dos contêineres foi realizada a partir de medições das condições climáticas do entorno, das temperaturas superficiais internas e externas da envoltória, bem como de variáveis que possibilitaram a análise de parâmetros de desempenho, conforto e estresse térmicos internos, como será apresentado a seguir.

Para a avaliação do Conforto Térmico foi utilizado o método do Conforto Adaptativo (ASHRAE, 2013), que possibilita a avaliação térmica de ambientes naturalmente ventilados. Tal método considera que há uma faixa relativamente ampla de satisfação térmica dos usuários que, podendo alterar variáveis relacionadas ao isolamento da roupa e aos controles de ganho de calor da edificação, como abertura e fechamento de portas e janelas, poderiam atingir índices satisfatórios de conforto sem que para tanto houvesse a necessidade de utilizar o condicionamento artificial. O método utiliza três categorias principais para a avaliação da satisfação térmica dos usuários: satisfação térmica de até $90 \%$ dos usuários, satisfação térmica de até $80 \%$ dos usuários (com tendência para o frio ou para o calor) e pontos localizados fora 
dos padrões de satisfação, situados em zonas cujos dados foram obtidos a partir de medições em situação de frio ou calor.

Os resultados obtidos a partir da medição realizada durante um ano no interior dos contêineres demonstraram que há insuficiência em relação ao comportamento termofísico da envoltória ao se avaliar o conforto térmico dos usuários tanto para situações de calor, quanto para situações de frio (Tabela 2).

Tabela 2 - Avaliação da satisfação térmica no interior do contêiner.

\begin{tabular}{|c|c|c|c|c|c|}
\hline Parâmetro & $\begin{array}{l}\text { Até } 90 \text { \% de } \\
\text { satisfação } \\
\text { térmica }\end{array}$ & $\begin{array}{l}\text { Até } 80 \% \text { de } \\
\text { satisfação } \\
\text { térmica } \\
\text { (tendência } \\
\text { ao calor) }\end{array}$ & $\begin{array}{l}\text { Até } 80 \% \text { de } \\
\text { satisfação } \\
\text { térmica } \\
\text { (tendência } \\
\text { ao frio) }\end{array}$ & $\begin{array}{l}\text { Fora dos } \\
\text { parâmetros } \\
\text { de satisfação } \\
\text { térmica } \\
\text { (calor) }\end{array}$ & $\begin{array}{l}\text { Fora dos } \\
\text { parâmetros } \\
\text { de satisfação } \\
\text { térmica (frio) }\end{array}$ \\
\hline Percentual (\%) & 13 & 2 & 5 & 31 & 49 \\
\hline
\end{tabular}

Os dados apresentados na Tabela 2 demonstram que a predominância de pontos situa-se fora dos limites de conforto considerados pelo método. O fato surpreendente, no entanto, é a constatação de que o maior percentual de pontos fora dos parâmetros de conforto refere-se a situações de frio para a Zona Bioclimática 3, e não de calor, conforme informações obtidas nos relatos colhidos em campo.

A insuficiência térmica da envoltória dos contêineres pode, porém, atingir níveis que levem a comprometer a condição de permanência do ser humano em seu interior em situações de calor, principalmente sob a incidência de radiação solar direta. Na pesquisa de mestrado citada previamente (COSTA, 2015), foram constatados momentos em que a temperatura do ar interno extrapolou o parâmetro do desconforto térmico, atingindo o que se denomina por estresse térmico. Sob situações de estresse térmico, o ser humano pode sofrer comprometimento de sua condição física, fato que respalda a NR-15 - Atividades e operações insalubres (BRASIL, 1978) estabelecer reduções da jornada de trabalho em tais situações.

Durante as medições, foram constatados episódios de estresse térmico no interior do contêiner sem tratamento térmico da envoltória, ocorridos principalmente nos horários mais quentes dos dias, em função da radiação solar direta a que essas instalações estavam submetidas. No mês de fevereiro - o mais quente do ano na região onde ocorreu o experimento - foram registradas até 4 horas por dia, em média, de condições de estresse térmico. Segundo a NR-15 - Atividades e operações insalubres, $82 \%$ do tempo sob estresse térmico registrado na pesquisa experimental, levaria a 
uma redução de jornada de 15 minutos a cada hora de trabalho, enquanto 18\% dos valores registrados levariam à redução de meia hora a cada hora trabalhada.

A envoltória apresenta insuficiência térmica também para situações de frio. No decorrer do ano experimental, foram registrados - durante as noites mais frias do ano e também durante o dia, no inverno, nos períodos sem radiação solar - momentos em que o frio ultrapassou a situação de desconforto, atingindo o que se pode considerar estresse térmico. Embora não tenham sido constatados momentos em que houvesse risco de congelamento ao corpo humano, durante o mês de agosto - mês mais frio no decorrer das medições - constatou-se até 15 horas diárias, em média, de temperaturas abaixo de $10^{\circ} \mathrm{C}$ no interior do contêiner.

Com relação ao desempenho térmico estabelecido pelos parâmetros da ABNTNBR 15575-1 (ABNT, 2013), a Norma de Desempenho, o contêiner sem tratamento térmico da envoltória também demonstrou insuficiência: no mês cujos resultados são de melhor desempenho térmico, somente durante treze horas por dia, em média, a temperatura interna permaneceu dentro dos parâmetros da norma, enquanto no pior mês registrado, a média foi de apenas quatro horas por dia dentro dos parâmetros de desempenho, que considera a diferença entre temperaturas do ar externas e internas.

A Figura 4 apresenta o registro de temperaturas no termômetro de globo localizado no interior do contêiner sem tratamento térmico. Os valores obtidos a partir das medições de temperatura com esse sensor aproximam-se significativamente dos valores da temperatura do ar interno, ou temperatura de bulbo seco, permenecendo a diferença entre as medições com os dois sensores situada na casa do décimo de grau.

(a)

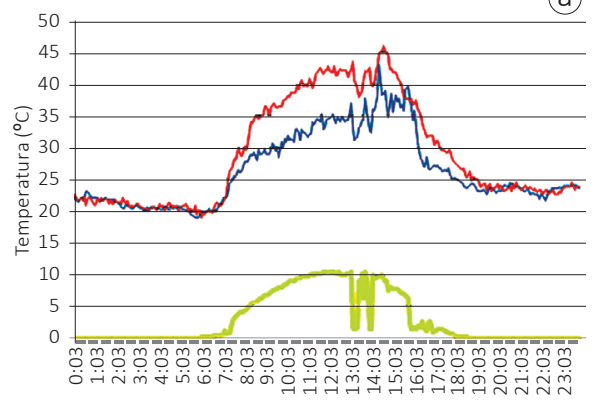

Tempo (h)

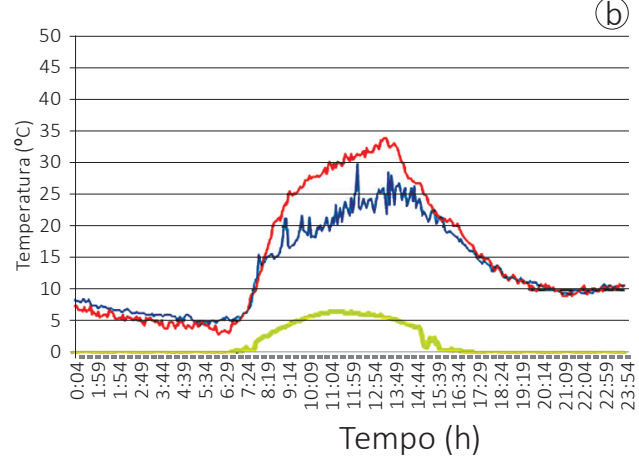

TBS Externa $\left({ }^{\circ} \mathrm{C}\right)$

Irradiação x 0,01 (W/m²)

— Temperatura de Globo $\left({ }^{\circ} \mathrm{C}\right)$ 
Figura 4 - Comportamento do termômetro de globo no dia mais quente (a) e no dia mais frio (b) no interior do contêiner sem tratamento térmico.

No verão, no horário mais quente, a temperatura de globo supera os $45^{\circ} \mathrm{C}$. No inverno, a temperatura no interior do contêiner atinge valor inferior a $4^{\circ} \mathrm{C}$ pouco antes do amanhecer.

\section{Estratégias de Tratamento Térmico para Contêineres em Canteiros de Obra}

Conforme apresentado nas análises do comportamento termofísico dos contêineres, o desempenho térmico da envoltória é insuficiente tanto para situações de frio quanto para situações de calor. As recomendações da NBR-15220-3 (ABNT, 2005) para o tratamento térmico da envoltória de edifícios convencionais situados na Zona Bioclimática Brasileira $n^{\circ} 3$ - local onde ocorreram as medições experimentais são a priorização da ventilação cruzada no verão e o aquecimento solar aliado à inércia térmica da envoltória no inverno. Os contêineres, no entanto, não se enquadram na categoria das edificações convencionais, dado que não têm inércia térmica significativa na envoltória e possuem limitações quanto à adição de massa térmica como estratégia de projeto, pois isso limitaria sua flexibilidade e mobilidade, parâmetros característicos desse tipo de instalação, sendo também algumas das características mais atraentes no momento de sua escolha como tipologia para canteiros de obras.

O experimento realizado na pesquisa de mestrado citada anteriormente (COSTA, 2015) contou com mais dois contêineres, além do contêiner sem tratamento térmico já descrito em análise do comportamento termofísico. O primeiro, dotado de tratamento da envoltória à condução, contava com uma camada de EPS de $2 \mathrm{~cm}$ sob a cobertura e no fechamento vertical, bem como com um forro de chapa dura de madeira de 0,25 mm para melhoria da qualidade de acabamento interno; o segundo, por sua vez, contava com tratamento da envoltória à radiação solar, tendo recebido aplicação de uma camada de 0,25 $\mu \mathrm{m}$ de revestimento refletivo branco em toda a envoltória, externamente.

\subsection{Diminuição do Ganho Térmico sob Radiação Solar - Uso Predominante em Programas de Ocupação Humana no Período Diurno ou em Ambientes Quentes}

A pesquisa experimental demonstrou que o contêiner com revestimento refletivo apresenta os melhores resultados quanto à diminuição do ganho de calor 
pela envoltória sob radiação solar direta ou em situações de calor, ainda que sem a presença de radiação solar.

O revestimento utilizado no modelo experimental foi o produto Nanothermic 1, desenvolvido, fabricado e comercializado pela empresa Nanotech do Brasil. O revestimento é composto de partículas com elevados índices de refletância e emissividade, característica que confere ao produto a qualidade de atingir menores temperaturas superficiais, em comparação aos materiais convencionais. Sua aplicação é realizada de modo simples, com uma bomba de pressão e, se realizada sob temperaturas de amenas a quentes, possui excelente aderência às superfícies metálicas dos contêineres.

A Figura 5 apresenta o registro das temperaturas de globo registradas no interior do contêiner durante os dias mais quente e mais frio, respectivamente.

(a)
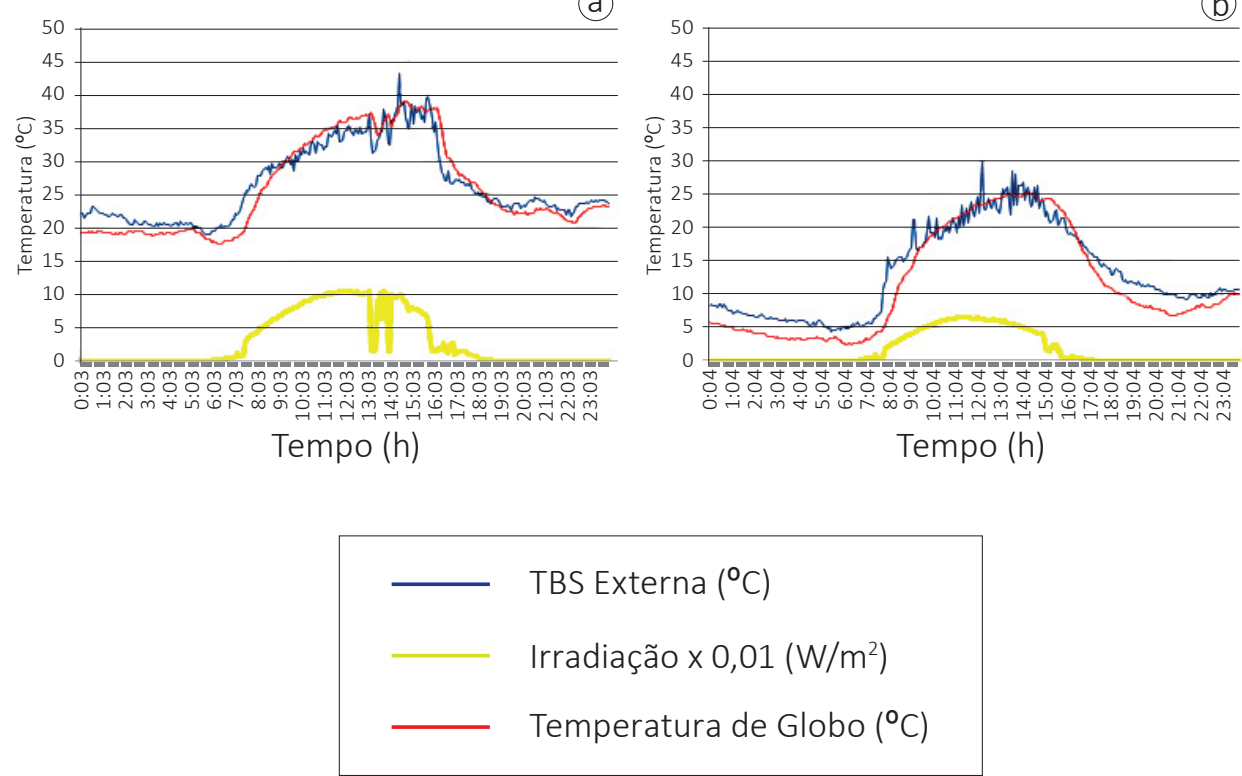

Figura 5 - Comportamento do termômetro de globo no dia mais quente (a) e no dia mais frio (b) no interior do contêiner com revestimento refletivo.

A temperatura de globo atinge os $38^{\circ} \mathrm{C}$ aproximadamente, na hora mais quente no dia de verão, enquanto no inverno, a menor temperatura registrada no interior do contêiner é inferior a $3^{\circ} \mathrm{C}$. O resultado de temperatura interna sob condição de calor no contêiner com revestimento refletivo foi o melhor valor obtido entre os três contêineres estudados. 


\subsection{Conservação do Calor no Interior do Contêiner: Uso Predominante em Programas de Ocupação Humana no Período Noturno}

Os resultados obtidos para o contêiner que recebeu tratamento térmico com o objetivo de aumentar a resistência à condução demonstram que o isolamento térmico executado com poliestireno expandido e chapa de madeira, como feito na cobertura, tem grande capacidade de redução do ganho de calor para o interior do contêiner, bem como na redução de perdas durante os períodos de resfriamento, como apresentado na Figura 6. Tal sistema de isolamento seria viável também para a utilização do contêiner com condicionadores de ar, diminuindo a demanda por energia elétrica para manter a temperatura dentro dos padrões de conforto, se comparado aos valores obtidos para o contêiner sem tratamento térmico.

(a)

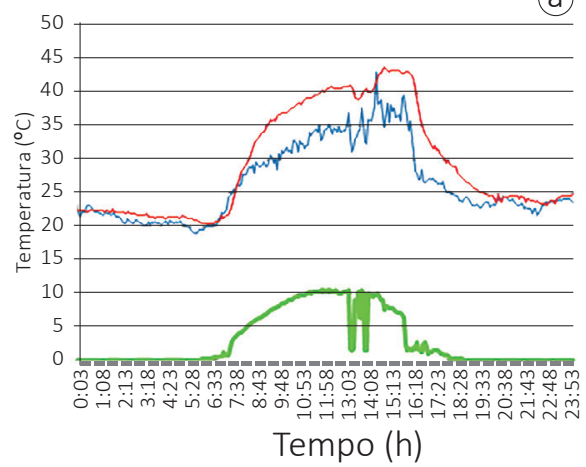

(b)

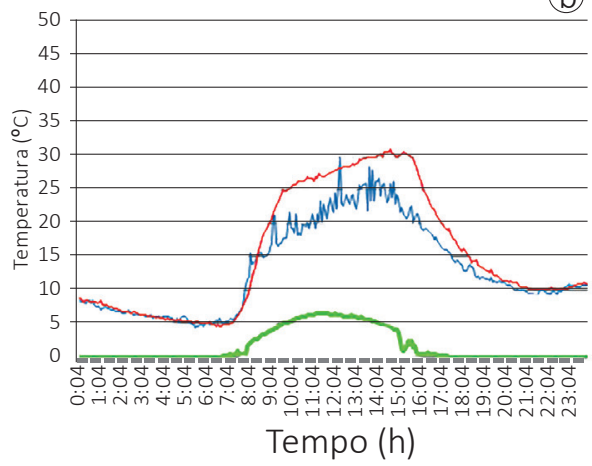

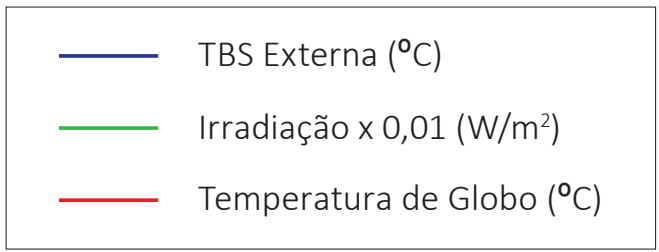

Figura 6 - Comportamento do termômetro de globo no dia mais quente (a) e no dia mais frio (b) no interior do contêiner com tratamento à condução.

No dia mais quente de verão, a temperatura interna atinge os $43^{\circ} \mathrm{C}$, aproximadamente, enquanto no dia mais frio de inverno, a temperatura de globo atinge os $5^{\circ} \mathrm{C}$, sendo esse o melhor resultado obtido para o frio entre os três contêineres estudados. 


\section{Comparação Anual entre os Três Contêineres - Soma dos Graus-hora}

O método dos graus-hora consiste na somatória das diferenças de temperatura entre a temperatura de referência ou temperatura de base - definida a partir de condicionantes locais - e as temperaturas medidas ou simuladas em determinado contexto.

As temperaturas de base são definidas em um intervalo no qual - para aquela determinada região climática - seja possível manter níveis de conforto sem que haja a necessidade da utilização de condicionadores artificiais (CIBSE, 2006). No presente estudo, foram consideradas como temperaturas de base os $20^{\circ} \mathrm{C}$ como temperatura mínima e $26^{\circ} \mathrm{C}$ como temperatura máxima. Tal definição implica no entendimento de que quando temperaturas abaixo de $20^{\circ} \mathrm{C}$ são registradas em medição, haveria a necessidade de aquecimento do ambiente, e quando temperaturas acima de $26^{\circ} \mathrm{C}$ são registradas, haveria a necessidade de resfriamento do ambiente.

O resultado final dos graus-hora é obtido pelo registro da diferença horária entre a temperatura de globo registrada e a temperatura de base. Se a temperatura de globo estiver acima dos $26^{\circ} \mathrm{C}$, a diferença é registrada como hora de resfriamento e, se estiver abaixo dos $20^{\circ} \mathrm{C}$, é registrada como hora de aquecimento. A somatória total das horas de aquecimento e resfriamento resulta no que se denomina graus-hora.

\subsection{Graus-hora de Aquecimento}

Conforme observado anteriormente, o registro das horas de aquecimento foi obtido nos momentos de ausência da radiação solar. No verão, tal fato ocorreu durante os períodos noturnos e, no inverno, a partir do momento em que a radiação solar direta desaparecia.

O resultado final apresentado na Figura 7 demonstra que os três contêineres alcançam valores altíssimos de horas de aquecimento, sendo o Contêiner à condução aquele que apresentou maior eficiência entre os três. Os resultados do Contêiner refletivo - cuja temperatura superficial externa é inferior à dos demais - foi extremamente negativo, demonstrando que em uma edificação cuja envoltória possui baixa resistência térmica, a temperatura superficial pode exercer influência sobre os níveis de conforto e o consumo energético. 


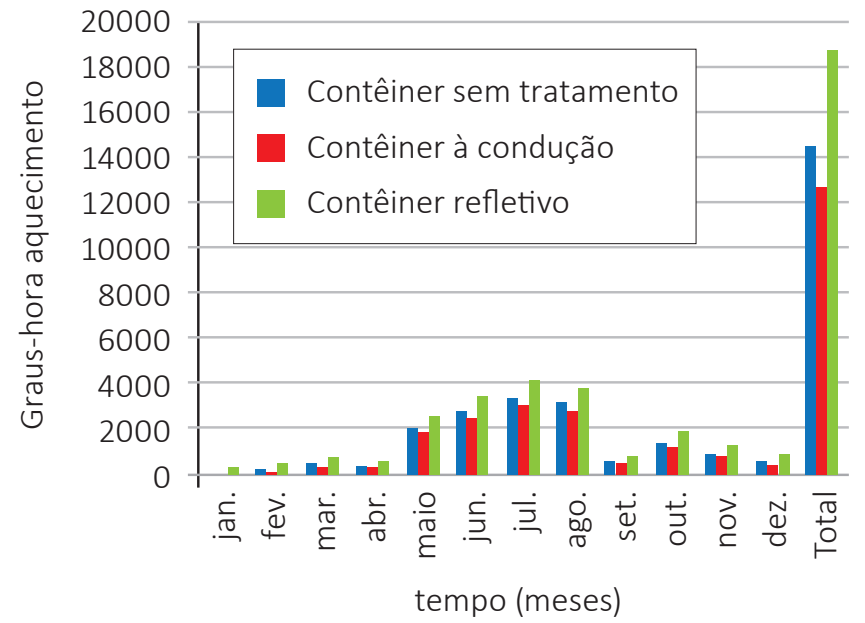

Figura 7 - Graus-hora: horas de aquecimento para os três contêineres.

\subsection{Graus-hora de Resfriamento}

As horas de resfriamento foram obtidas frequentemente sob a ação da radiação solar. Nota-se, como aparece na Figura 8, que os resultados finais são inferiores ao das horas de aquecimento, demonstrando que apesar de haver insatisfação por parte de usuários questionados em conversas informais quanto ao comportamento térmico dos contêineres no calor, seu desempenho térmico é ainda pior no frio.

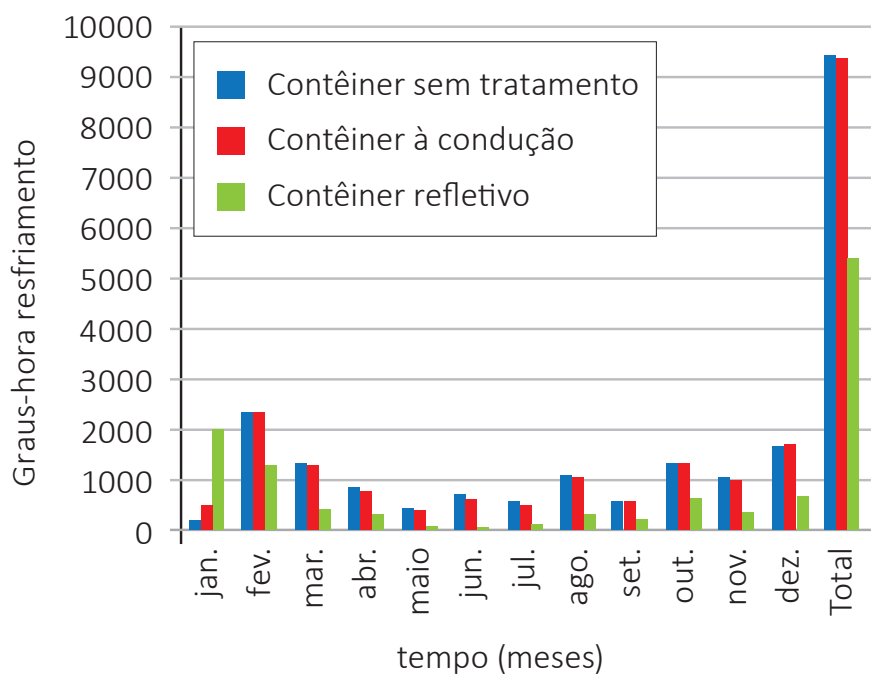

Figura 8 - Graus-hora: horas de resfriamento para os três contêineres. 
O Contêiner sem tratamento apresentou os piores resultados para as horas de resfriamento, totalizando 9423 horas. No Contêiner à condução, registrou-se $97 \%$ das horas de resfriamento obtidas no Contêiner sem tratamento, enquanto no Contêiner refletivo, obteve-se o surpreendente resultado de $38 \%$.

\section{Conclusões}

A envoltória dos contêineres metálicos possui características que a tornam insuficiente do ponto de vista do desempenho térmico. Sua baixa inércia térmica leva as superfícies a variações bruscas de temperatura, situação que consequentemente se registra também no interior dessas instalações. Dessa forma, quando se pretende a utilização sob condicionamento passivo, isto é, sem a utilização de condicionadores artificiais, é necessário que se determine previamente a localidade na qual o contêiner será utilizado, considerando principalmente suas condições climáticas, como também o tipo de uso predominante a que o contêiner será destinado: se diurno ou noturno. Seu desempenho térmico insuficiente prejudica a adoção de uma única solução de tratamento térmico da envoltória para toda e qualquer situação quando se objetiva o condicionamento passivo ou mesmo a redução do consumo energético para condicionamento artificial.

O Quadro 1 apresenta um resumo das diretrizes para uso mais adequado à obtenção de padrões aceitáveis de conforto térmico e eficiência energética nos climas brasileiros.

Quadro 1 - Tratamento térmico da envoltória para melhor desempenho térmico dos contêineres para canteiros de obras.

\begin{tabular}{|c|c|c|c|c|c|}
\hline & \multirow[b]{2}{*}{ Clima } & \multicolumn{2}{|c|}{ Com Condicionamento Artificial } & \multicolumn{2}{|c|}{ Sem Condicionamento Artificial } \\
\hline & & Quente & Frio & Quente & Frio \\
\hline \multirow{2}{*}{ 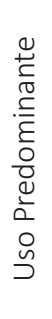 } & Diurno & $\begin{array}{l}\text { revestimento } \\
\text { refletivo + } \\
\text { isolamento à } \\
\text { condução }\end{array}$ & $\begin{array}{l}\text { isolamento à } \\
\text { condução }\end{array}$ & $\begin{array}{l}\text { revestimento refletivo } \\
+ \text { isolamento à } \\
\text { condução sob a } \\
\text { cobertura }\end{array}$ & $\begin{array}{l}\text { isolamento à } \\
\text { condução }\end{array}$ \\
\hline & Noturno & $\begin{array}{l}\text { revestimento } \\
\text { refletivo + } \\
\text { isolamento à } \\
\text { condução }\end{array}$ & $\begin{array}{l}\text { isolamento à } \\
\text { condução }\end{array}$ & revestimento refletivo & $\begin{array}{l}\text { isolamento à } \\
\text { condução }\end{array}$ \\
\hline
\end{tabular}

A aplicação do revestimento refletivo apresenta-se como uma solução durável e de baixo custo para a utilização dos contêineres. Para que as propriedades do 
revestimento sejam amplamente aproveitadas na diminuição do ganho térmico, percebe-se que a utilização do revestimento resistente à radiação se faz adequada em contêineres que se destinem prioritariamente ao uso em atividades exercidas durante o dia nos canteiros de obras, como é o caso do trabalho nos escritórios, ou ainda em usos predominantemente noturnos em localidades de clima quente de dia e à noite. Ainda que haja necessidade da utilização de climatizadores artificiais no verão, a demanda por energia será minimizada.

$\mathrm{O}$ isolamento térmico da envoltória com os tradicionais materiais isolantes EPS, poliuretano e demais fibras - aplica-se aos casos nos quais se pretende conservar o calor internamente, como acontece nos contêineres destinados a dormitórios de trabalhadores em climas amenos ou frios. O isolante térmico também pode ser utilizado nos casos em que se pretende minimizar as trocas entre o ar externo e interno, como nas situações em que se opta por condicionamento artificial.

Para os climas quentes, a utilização de uma solução mista que empregue o revestimento refletivo externamente na envoltória somado ao tratamento da cobertura à condução teria grande potencial de diminuição de ganho térmico no interior dos contêineres.

No caso do uso em localidades quentes cuja necessidade de condicionamento artificial é premente, a demanda por energia seria minimizada com a utilização de ambos os tratamentos térmicos simultaneamente: a aplicação de revestimento refletivo e o isolamento térmico à condução na envoltória.

\section{Referências}

ASHRAE. American Society of Heating, Refrigerating and Air-Conditioning Engineers, INC. ASHRAE STANDART 55-2013. Thermal Environmental Conditions for Human Occupancy. 2013.

ABNT. Associação Brasileira de Normas Técnicas. NBR 15220-3 - Desempenho térmico de edificações - Parte 3: Zoneamento Bioclimático brasileiro e diretrizes construtivas para habitações unifamiliares de interesse social. 2005.

ABNT. Associação Brasileira de Normas Técnicas. NBR 15575-1 - Edificações Habitacionais Desempenho Parte 1: Requisitos Gerais. 2013.

BRASIL. Ministério do Trabalho e Emprego. Norma Regulamentadora 15 (NR15) - Atividades e Operações Insalubres - Anexo III - Limites de Tolerância para Exposição ao Calor. 1978. Disponível em: <http://portal.mte.gov.br/data/ files/8A7C816A47594D040147D14EAE840951/NR-15\%20(atualizada\%202014).pdf>. Acesso em: nov. 2014.

CIBSE. The Chartered Institution of Building Services Engineers. Degree-days - theory and application - tm41 2006. [S.I.]: CIBSE, 2006. 
COSTA, D.C.R.F. Contêineres metálicos para canteiros de obras: análise experimental de desempenho térmico e melhorias na transferência de calor pela envoltória. Dissertação (Mestrado) - Escola Politécnica da Universidade de São Paulo. São Paulo, 2015.

OLIVEIRA, M.E.R.; LEÃO, S.M.C. Planejamento das Instalações de Canteiros de Obras: Aspectos que Interferem na Produtividade. ENEGEP 1997, 1997. Disponível em: <http:// www.abepro.org.br/biblioteca/ENEGEP1997_T3308.PDF>. Acesso em: jun. 2014.

SANTAMOURIS, M.; KOLOKOTSA, D. Passive cooling dissipation techniques for buildings and other structures: The state of the art. Energy and Buildings, v. 57, p. 74-94, fev. 2013.

SAURIN, T. A.; FORMOSO, C. T. Planejamento de canteiros de obra e gestão de processos. Porto Alegre: ANTAC, 2006. 